Prepacked Milk Feeds for Continuous Intragastric Feeding

SIR,-I was interested in Drs. G. A. Faux and H. B. Valman's comments (8 September, p. 543). I have been using prepacked milk for continuous intragastric feeding for over a year and have found this method to be most useful in babies below $1.5 \mathrm{~kg}$. Volumes as small as $2 \mathrm{ml}$ of milk per hour may initially be needed in babies of very low birth weight. The calibration of readyto-feed bottles is usually in $15 \mathrm{ml}$ marks, and with the bottle inverted the last $50 \mathrm{ml}$ (approximately) is uncalibrated. This bottle, combined with a standard blood transfusion giving set, leads in my experience to difficulty in controlling the flow rate of small volumes of milk. The practice here is to use a paediatric giving set, incorporating a 100 ml burette calibrated in $1 \mathrm{ml}$ marks, as a reservoir for the millk, and to combine this with a constant infusion pump. The milk is changed six-hourly and no difficulty has arisen in keeping the milk sterile. In this way very accurate fluid intake can be achieved.-I am, etc.,

Robroyston Hospital

ROSEMARY S. SHANNON Glasgow

\section{Depressed Fracture in the Newborn}

SIR,-Depressed fracture of the skull in the newborn is often a result of feto-maternal disproportion or instrumental delivery, and elevation by open operation is usually recommended. We believe it is worthwhile publicising a method of elevation using a Malstrom vacuum extractor which we have found successful. It has the advantage of ease, and anaesthesia and open surgery are avoided. Though originality for the technique cannot be claimed it seems to be little known.

A multiparous woman was admitted to hospital at term in the second stage of labour. An arm had prolapsed in front of the head but before treatment could be given spontaneous delivery occurred. Soon after delivery the infant was noted to have a large pond fracture of the frontal bone where it had underlain the humerus (fig. 1). A medium vacuum cup was applied over the depression and a caput slowly raised. Traction was applied gently at first and slowly increased. When what was considered to be maximum safe traction was applied a slight "give" was felt. The large caput prevented clinical assessment but radiography (fig. 2)

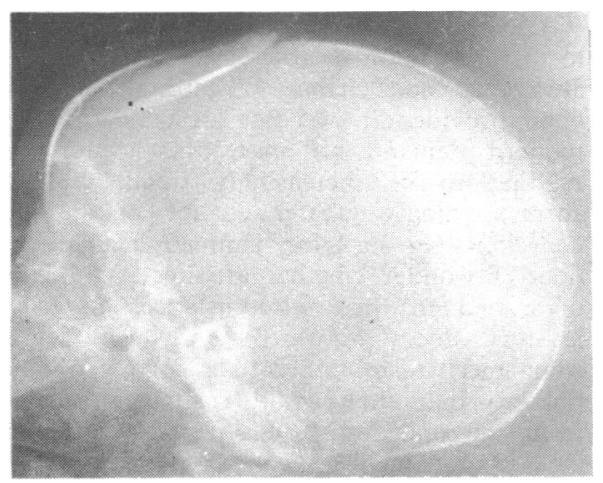

Fig. 1

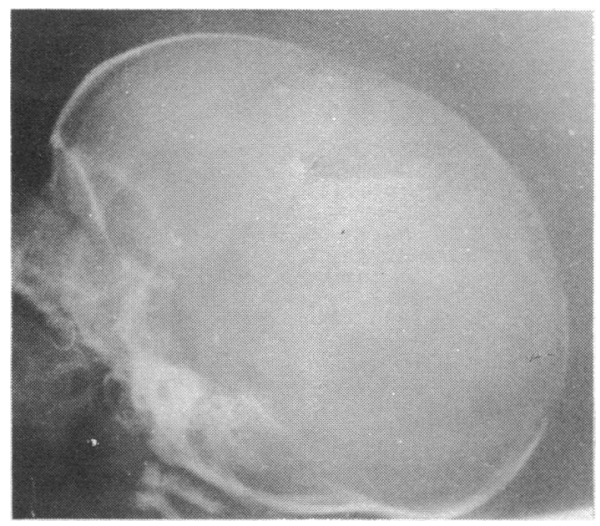

fractions following chromatography did not contain sufficient material to produce any growth on microbiological assay.-We are, etc.,

Clinical Research Centre,

JANet Perry

I. Chanarin

Harrow

\title{
Abuse of Psychiatry
}

SIR,-I read with dismay the appallingly dilute resolution passed by the Representative Body of the B.M.A. as quoted in your leading article (8 September, p. 509).

The resolution fails completely to conFig. 2 demn the "doctors" themselves who are guilty of infamous conduct in prostituting their power to commit patients to hospital,

revealed that reduction was complete. The baby appeared to suffer no ill effects.

We feel that this method is unlikely in practice to be more traumatic than open elevation, and apart from simplicity it has the advantage of possible immediate application after delivery when reduction should be easiest. It may be worthwhile using this method as a first line treatment before proceeding to more complex methods in the event of failure.-We are, etc.

Nchanga North Hospital,

J. W. KYLE Chingola, Zambia

D. JENKINSON

\section{Conference of Royal Colleges and Faculties} in Scotland

SIR,-I was surprised to notice the omission of the Scottish Branch of the Faculty of Homoeopathy from this deliberative body (22 September, p. 641). This must surely have been an oversight, as homoeopathy has been taught as a postgraduate subject for almost 100 years and has been an integral part of the National Health Service since its inception, at hospital and general practitioner levels.

The homoeopathic representations in the European Common Market-and beyond, in Russia-underline the need for homoeopathic participation. I am certain that the inclusion of our representative would strengthen the deliberations of the conference both in Scotland and abroad, where we already have a liaison through the International Homoeopathic League.-I am, etc.,

C. OLIVER KENNEDY Faculty of Homoeopathy

\section{Formylation of Folate}

SIR,-In our paper (9 June, p. 588) we showed that in the transport of folate across the gut wall of the rat, formylation as well as reduction of folate occurred. Drs. J. A Blair and J. R. G. Beavon (15 September, p. 591) consider that our results are due to oxidation of endogenous folate. We are happy to be able to inform them that they are mistaken. In control experiments we measured endogenous folate by incubating the everted rat gut preparation with Krebs Ringer bicarbonate, plus glucose alone without added folate. Only trace amounts of folate appeared in the serosal fluid, and the or in prescribing drugs with the express intention of actually inducing a pathological state. The resolution should surely state clearly and loudly that no exchanges whatsoever will be countenanced with such practitioners.

I am, along with many of my professional colleagues, gravely concerned by what we see as a terrible erosion of professional principles, one of which is a primary responsibility to the patient and a refusal to become an agent of a regime in contravention of that responsibility.

Our profession has surely reached a low ebb when it sees fit to meet in the very country concerned with those who have abused their professional status and abrogated all claim to professional integrity and recognition.-I am, etc.,

Michael T. MOORE

Midlands Postal Region Headquarters, Birmingham

\section{Psychiatric Nurse as Therapist}

SIR,-I was delighted to read the article by Dr. I. M. Marks and others (21 July, p. 156). I have been encouraging psychiatric nurses in hospital and clinic as well as domiciliary practice to work as therapists for many years. ${ }^{2}$ There have been occasions in my own clinic practice when general practitioners felt that their patients were being shortchanged with psychiatric nurses working there as therapists, even with my regular supervision, but I believe this article will inform our general practitioner colleagues, who refer most of our patients, about psychiatric nurse skills. A further in vestment is the way psychiatrists and psychiatric nurses learn together as trainees. What is not clarified in the article, however, is a shift from the traditional psychiatric nurse's role. There is a difference, for example, between the nurse's interpretation of the patient's experience to the psychiatrist or psychologist (therapist) or the ways of working of the therapist to the patient in a traditional manner and her interpretation of the patient's experience to the patient. In the former technique closeness with the patient is very important, whereas with the latter a certain distance between patient and therapist is necessary. Another disconcerting feature of the article for me was the way the authors lumped together "a wide range of skills." In my experience training techniques for any parti- 